\title{
NACIS Student Dynamic Map Competition
}

Mathew A. Dooley, Ph.D. | Mathew.dooley@uwrf.edu

Department of Geography and Mapping Sciences

University of Wisconsin-River Falls

410 S. 3rd St.

River Falls, WI 54022

The Student Dynamic Map Competition provides an opportunity for students to demonstrate their skills in dynamic map design. The 2010 competition winners are high-quality works that illustrate state-ofthe-art techniques.

The 2010 winner for best Narrative map is The Chernobyl Disaster by Kate Chanba, Matt Forrest, Vanessa Knoppke-Wetzel, and Andrew Wilson. This map tells the story of the Chernobyl disaster from both a European and Ukrainian perspective. In addition to various reference and thematic maps, a slideshow and accompanying narrative shed light on the human side of the tragedy.

The 2010 winner for best Interactive map is placebook: Social Map by Zdenek Hynek and Martin Pulicar. This example

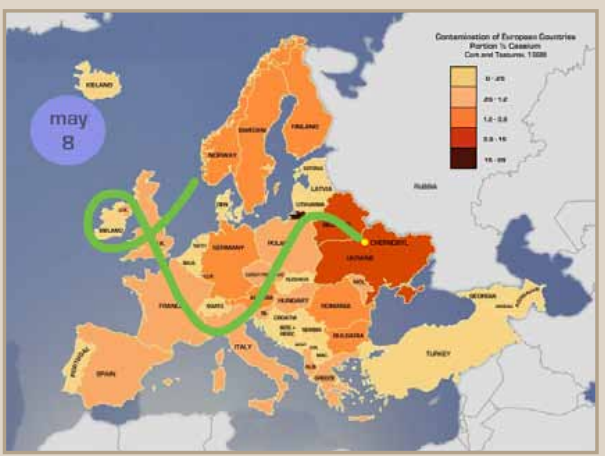

2010 winner for best Narrative map uses a dynamic choropleth map, as well as interactive tables and graphs, to show the number and proportion of Facebook users by country worldwide. This map is truly interactive and informative, with well-designed mouseovers and dynamic graphics throughout.

This year's competition offers a $\$ 500$ prize for best Narrative map and a $\$ 500$ prize for best Interactive map.

Any student enrolled in a degree or certificate program may enter. Instructors, please encourage your students to submit a map in either category today!

For complete rules and submission guidelines, please visit the website:

$\mathrm{http}: / /$ www.nacis.org/index.cfm? $\mathrm{x}=4$

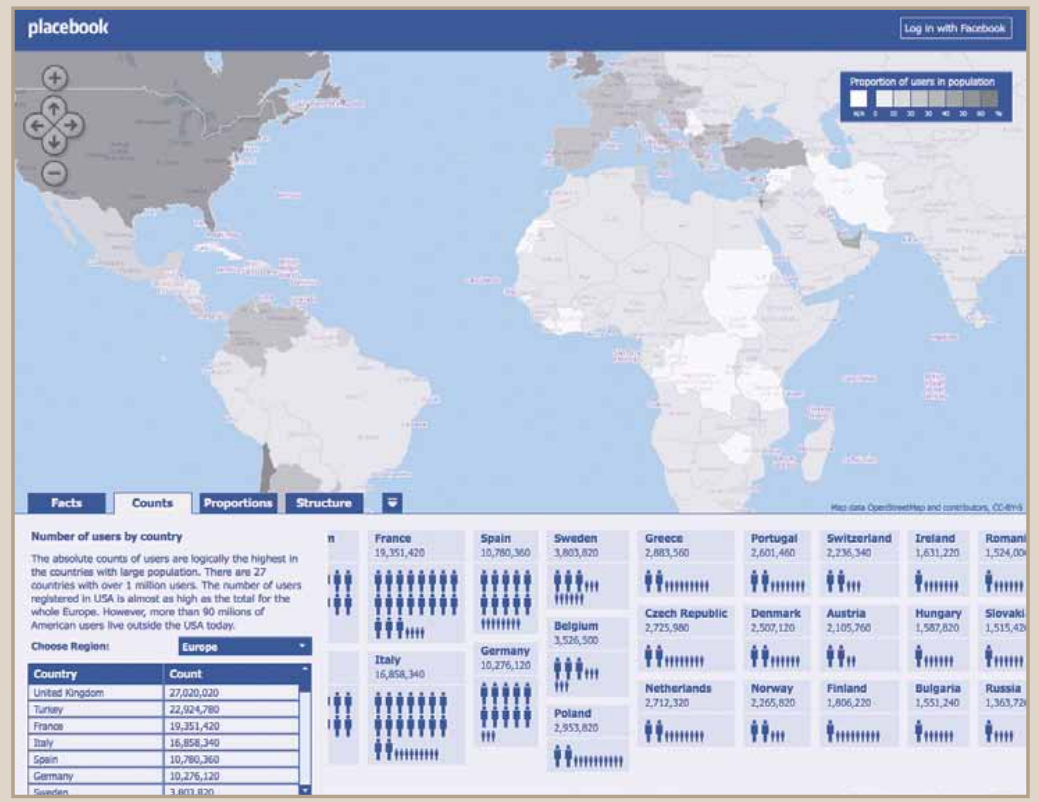

2010 winner for best Interactive map 